\title{
Evaluation of Different Soil Salinity Mapping Using Remote Sensing Techniques in Arid Ecosystems, Saudi Arabia
}

\author{
Mohamed Elhag \\ Department of Hydrology and Water Resources Management, Faculty of Meteorology, Environment \& Arid Land Agriculture, \\ King Abdulaziz University, Jeddah 21589, Saudi Arabia
}

Correspondence should be addressed to Mohamed Elhag; melhag@kau.edu.sa

Received 14 July 2015; Revised 12 November 2015; Accepted 2 December 2015

Academic Editor: Guiyun Tian

Copyright (C) 2016 Mohamed Elhag. This is an open access article distributed under the Creative Commons Attribution License, which permits unrestricted use, distribution, and reproduction in any medium, provided the original work is properly cited.

Land covers in Saudi Arabia are generally described as salty soils with sand dunes and sand sheets. Waterlogging and higher soil salinity are major challenges to sustaining agricultural practices in Saudi Arabia principally within closed drainage basins. Agricultural practices in Saudi Arabia were flourishing in the last two decades. The newly reclaimed lands were added annually and distributed all over the country. Irrigation techniques are mostly modernized to fulfill water saving strategies. Nevertheless, water resources in Saudi Arabia are under stress and groundwater levels are depleted rapidly due to heavy abstraction that may exceed crop water requirements in most of the cases due to high evaporation rates. The excess use of irrigational water leads to severe soil salinity problems. Applications of remote sensing technique in agricultural practices became widely distinctive and cover multidisciplinary principal interests on both local and regional levels. The most important remote sensing applications in agricultural practices are vegetation indices which are related to vegetation and water especially in an arid environment. Soil salinity mapping in an arid ecosystem using remote sensing data is a demanding task. Several soil salinity indices were implemented and evaluated to detect soil salinity effectively and quantitatively. Thematic maps of soil salinity were satisfactorily produced and assessed.

\section{Introduction}

Saudi Arabia has practiced an eminent development in vital sectors over the last three decades. As a result, rapid escalation in terms of water demands in domestic, industrial, and agricultural activities have been countersigned. Agriculture is the keystone water consumption sector; it consumes about $85 \%$ of total national water use (Ministry of Water and Electricity) [1]. During the period of 1974-2006, Saudi Arabian government subsidized the agricultural sector to improve living standards in urban areas and to achieve sustainability. These subsidies lead to significant increases in agricultural areas, primarily for rigorous irrigated crops such as wheat, maize, and alfalfa; the irrigated areas increased from less than 400,000 ha in 1971 to about 1.62 million ha in 1992 [2, 3]. The extensive groundwater extrication subsequently leads to higher soil salinity rates in most of the agricultural zones [46].

Excessive irrigation of less developed drained soil has led to high floating water tables, waterlogging, and soil salinization [7]. In the absence of well drainage network in shallow soil, water table depth intends to develop remarkably and, eventually, irrigable lands will be abandoned [8]. In the incidence of a higher soil salinity, crop production can be dramatically affected when salts accumulate in the soil surface [9-11]. Conservatively, soil salinity and waterlogging can be regulated through sustaining the salt concentration at the root zone below the crops constraint [12]. This can be realized by maintaining the equilibrium between soil recharge and discharge by draining the surplus irrigational water [13].

Dwivedi [14] used the first four bands of MSS to designate salty soils. Chaturvedi et al. [15] and Singh and Srivastav [16] used brightness and thermal temperature layers to detect soil salinity. Menenti et al. [17] used 3 bands of TM (1, 5, and 7) to detect salt minerals. Moreover, Mulders and Epema [18] used three different bands of TM $(3,4$, and 5) to detect calcareous surfaces as an indication of high salt content. Saha et al. [19] used the thermal infrared band of TM to classify inland waterlogged areas. Rao et al. [20] used the false color 
composition of TM bands (2, 3, and 4) to distinguish between moderate and high soil content soils. Naseri [21] used both unsupervised and supervised classification algorithms to delineate soil salinity on a regional scale using three bands of MSS and four bands of TM. Darvishsefat et al. [22] used principal component analysis to map soil salinity using four bands of ETM+ (3, 4, 5, and 7). Zhang et al. [23] used different bands of OLI-8 to develop a soil salinity detection algorithm based on the Soil Salinity Information Extraction (SSIE).

Implementation of remote sensing data in soil salinity mapping is firm to employ since salinization is not a static process. Therefore, a number of derivatives and alternatives to normalized difference vegetation index have been anticipated to discourse soils salinization monitoring and mapping [2426]. Different remote sensing indices such as the salinity index (SI), the normalized difference salinity index (NDSI), and the brightness index (BI) in addition to normalized difference vegetation index (NDVI) were implemented to investigate the means by which these indices work for soil salinity mapping in the arid environment [27, 28]. The salinity index (SI), which combines the blue and red bands, is sensitive to the surface reflectance of salt-affected land with sparse vegetation cover [27].

The perspective of using remote sensing data and GIS practices has been demonstrated in several scholarly works to be the most resourceful [29-32]. The comprehensive use of satellite remote sensing and GIS has been recognized to be a cost-effective method for monitoring soils salinization in poorly drained basins $[33,34]$. However, state-of-the-art outcome specifies that there is no ideal combination of data type and questioning method which can be functional with identical realization across approximately several environmental conditions [25-27].

The aim of current research project is to differentiate the salinized soils from nonsalinized soils implementing different approaches of digital image classification and band math techniques. To reach that objective, several soil salinity indices were applied to the Landsat 8 data verified with ground truth data to validate the percentage of estimations accuracy based on different error's assessment approach.

\section{Materials and Methods}

2.1. Study Area. The study area, Wadi Al Dawasir town, is located in the plateau of Najd at latitude of $44^{\circ} 43^{\prime}$ and longitude of $20^{\circ} 29^{\prime}$, about $300 \mathrm{~km}$ south of the capital city Riyadh (Figure 1). This study area is comprised of gravelly tableland disconnected by insignificant sandy oases and isolated mountain bundles. Across the Arabian Peninsula as a whole, the tableland slopes toward the east from an elevation of 1,360 meters in the west to 750 meters at its easternmost limit. Wadi Al Dawasir and Najran regions are the major irrigation water abstraction from Al-Wajid Aquifer. Agriculture in Wadi Al Dawasir area consists of technically highly developed farm enterprises that operate modern pivot irrigation system. The size of center pivot ranges from 30 ha to 60 ha with farms managing hundreds of pivots with the corresponding number of wells. The main crop grown

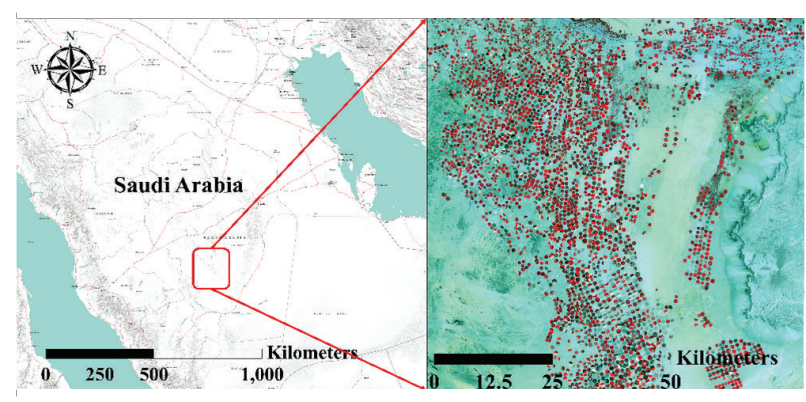

FIGURE 1: Location of the study area.

in winter is wheat and occasionally potatoes, tomatoes, or melons. All year fodder consists of alfalfa, which is cut up to 10 times a year for food. Typical summer crops for fodder are sorghum and Rhodes grass, which is perennial but dormant in winter. The shallow alluvial aquifers could not sustain the high groundwater abstraction rates for a long time and groundwater level declined dramatically in most areas. Meteorological features of the area are speckled. Five elements of meteorology are constantly recorded through fixed weather station located within the study area. Temperature varies from $6^{\circ} \mathrm{C}$ as minimum temperature to $43^{\circ} \mathrm{C}$ as maximum temperature. Relative humidity is mostly stable at $24 \%$. Solar radiation of average sunrise duration is generally $11 \mathrm{hrs} /$ day. Average wind speed is closer to $13 \mathrm{~km} / \mathrm{hr}$ and may reach up to $46 \mathrm{~km} / \mathrm{hr}$ in thunderstorm incidents. Finally, mean annual rainfall is about $37.6 \mathrm{~mm} \mathrm{[5].}$

2.2. Methodological Framework. The current research work is based on assessing a regression correlation between ground truth data and its corresponding salinity index's values conducted from satellite images. Therefore, accurate synchronization of ground truth data collection and satellite bypassing were exercised.

2.2.1. Soil Sampling and Analysis. A total number of 150 random soil samples were collected from Wadi Al Dawasir area with a minimum distance of $100 \mathrm{~m}$ between the samples locations to avoid data clumping (Figure 2). The standard procedure of determining soil extract salinity in terms of Electrical Conductivity (EC) was followed according to Shaw [35] under laboratory condition.

2.2.2. Remote Sensing Data Enhancement. Remote sensing data was obtained from Landsat Operational Land Imager (OLI-8) which was acquired on April 17th, 2014. Typical atmospheric and radiometric corrections and spatial resolution enhancement were implemented for each band individually. Furthermore, overcorrection was analyzed for the red and near infrared bands [36]. Atmospheric correction is basically considering blue band offset. Therefore, the largest atmospheric consequence is theoretical to be the most truthful value within the blue band. The calibrated radiance value of this offset allows deciding $\kappa$ value. Therefore, $\lambda^{-\kappa}$ rule 


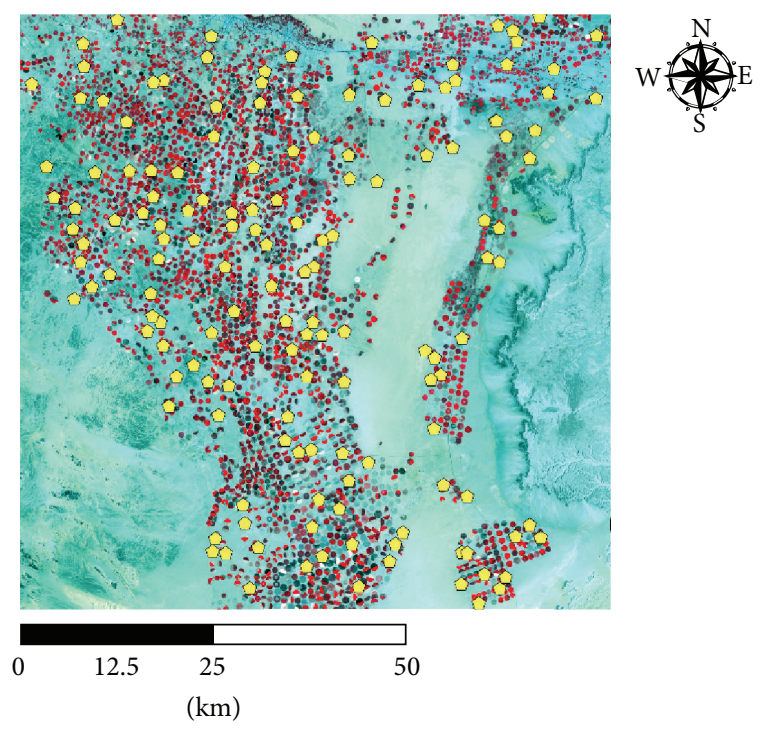

FIgURE 2: Soil sample location on false-color Landsat 8 image.

the offset values for the green, red, and near infrared band under investigation [37].

2.2.3. Soil Salinity Indices. Soil salinity detection using remote sensing techniques developed through several scholarly works. Landsat Multispectral Scanning (MSS), TM (Thematic Mapper), and Enhanced Thematic Mapper (ETM+) in addition to Operational Land Imager (OLI-8) images were the most used remote sensing data in soil salinity mapping. Several algorithms of detecting and mapping soil salinity were developed because of the sensors and/or study area variability. There were many attempts to use the remote sensing data and its techniques to detect the salt-affected soil. Soil salinity indices are principally adjusted to detect salt mineral in soils based on the different responses of salty soils to various spectral bands. Table 1 summarizes different indices used to map soil salinity in current study.

2.3. Validation. Linear regression model was used to validate the correlation established between the ground truths data measured from the 150 soil samples collected and the corresponding salinity index's values estimated using the aforementioned equations. Root square, root square adjusted, root mean square error, and mean of response are used to signify the inequality of variance and correlation of the linear regression model [38].

\section{Results and Discussion}

The use of different soil salinity equations gives the results the differential preferences to achieve an adequate soil salinity estimation on a large scale using remote sensing data. The evaluation of different soil salinity indices was based on the regression model fit, effect significance, and model parameters. Table 2 summarizes different regression significances.

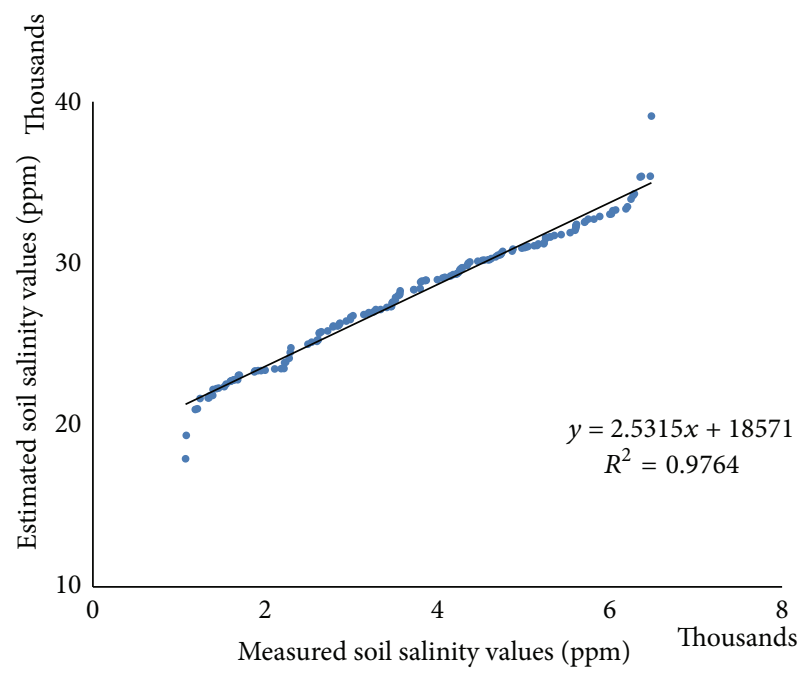

FIgURE 3: Linear regression between measured and estimated soil salinity values.

Based on different "errors" estimated by analysis of variance, SI-9 represents the most straightforward linear regression model. Figure 3 shows the correlation between the estimated soil salinity values using soil salinity index-9 and the collected ground truth values.

Due to the fact that the soil salinity indices used in the current research are varied (11 in total), categorization of different indices using principal component analysis will help decide which is similar/different to which. Figure 4 represents the grouping to different indices according to principal component analysis on covariances.

Generally, different soil salinity indices fell into two groups. SI-6, SI-9, SI-3, and BI are in one group and the rest are in the other group. SI- 6 and NDSI failed to join their corresponding group and remain as group outlier [39]. Lack of correlation is the main reason of the insignificance of SI-6 and NDSI. High correlation significance between SI-3, SI-9, and $\mathrm{BI}$ is the best to represent soil salinity indices according to Table 2.

The results proved the acceleration in the rate of vegetation death and soil salinization based on the high correlation between higher soil salinity values and negative normalized difference vegetation index with $R^{2}$ values of 0.92 [40]. Moreover, higher soil salinity was related to the improper and intense drainage systems set up in addition to the lack of an operative water resource management plan [41].

The dynamicity of the soil salinization process added further complications to designating salt-affected soils in a systematic uniform perspective. The use of different algorithms based on implementing different combinations and/or ratios of OLI- 8 bands in the form of soil salinity indices evidenced to be more efficient to overcome soil dynamicity problems $[23,42]$.

The selection of the sensitive bands adequate for proper soil salinity mapping is not systematically generalized [42, 47]. Spatial variability and land cover variations are the most limiting factors of band selection of a sensor [23, 48]. 
TABLE 1: Soil salinity indices based on different band ratios of Landsat.

\begin{tabular}{|c|c|c|}
\hline Salinity index & Band ratios & Reference \\
\hline Normalized difference salinity index & $\mathrm{NDSI}=\frac{(R-\mathrm{NIR})}{(R+\mathrm{NIR})}$ & {$[43]$} \\
\hline Brightness index & $\mathrm{BI}=\sqrt{\left(R^{2}+\mathrm{NIR}^{2}\right)}$ & {$[44]$} \\
\hline Salinity index-1 & $\mathrm{SI}=\sqrt{(B \times R)}$ & {$[44]$} \\
\hline Salinity index-2 & $\mathrm{SI}=\sqrt{(G \times R)}$ & {$[44]$} \\
\hline Salinity index-3 & $\mathrm{SI}=\sqrt{\left(G^{2}+R^{2}+\mathrm{NIR}^{2}\right)}$ & {$[27]$} \\
\hline Salinity index-4 & $\mathrm{SI}=\sqrt{\left(G^{2}+R^{2}\right)}$ & {$[27]$} \\
\hline Salinity index-5 & $\mathrm{SI}=\frac{B}{R}$ & {$[45]$} \\
\hline Salinity index-6 & $\mathrm{SI}=\frac{(B-R)}{(B+R)}$ & {$[45]$} \\
\hline Salinity index-7 & $\mathrm{SI}=\frac{(G \times R)}{B}$ & {$[45]$} \\
\hline Salinity index-8 & $\mathrm{SI}=\frac{(B \times R)}{G}$ & {$[46]$} \\
\hline Salinity index-9 & $\mathrm{SI}=\frac{(\mathrm{NIR} \times R)}{G}$ & {$[46]$} \\
\hline
\end{tabular}

$B$, blue band; $G$, green band; $R$, red band; NIR, near infrared band of Landsat 8 image.

TABLE 2: Regression significances.

\begin{tabular}{lccccccccccc}
\hline & NDSI & BI & SI-1 & SI-2 & SI-3 & SI-4 & SI-5 & SI-6 & SI-7 & SI-8 & SI-9 \\
\hline$R$ square & 0.62 & 0.94 & 0.89 & 0.90 & 0.95 & 0.90 & 0.44 & 0.44 & 0.91 & 0.86 & $\mathbf{0 . 9 8}$ \\
$R$ square adjusted & 0.62 & 0.94 & 0.89 & 0.90 & 0.95 & 0.90 & 0.44 & 0.44 & 0.91 & 0.86 & $\mathbf{0 . 9 8}$ \\
Root mean square error & 1.51 & 760.08 & 1000.38 & 1139.67 & 773.06 & 1638.87 & 0.29 & 0.29 & 1780.57 & 1266.35 & 603.14 \\
Mean of response & 0.01 & 30262 & 14749 & 15716 & 33634 & 22431 & 0.18 & 0.01 & 19408 & 14958 & $\mathbf{2 8 1 0 3}$ \\
\hline
\end{tabular}

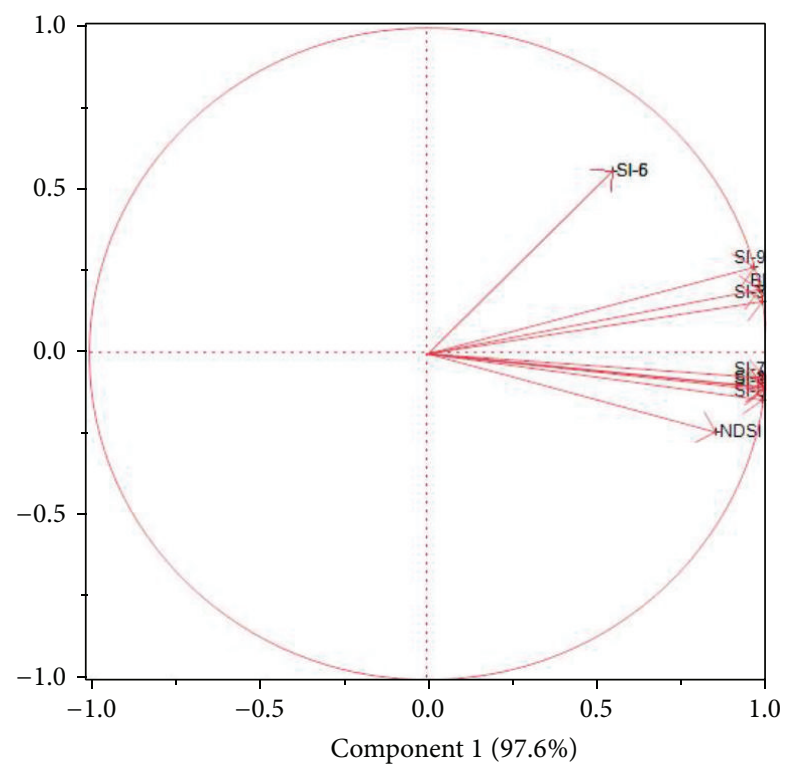

FIGURE 4: Variance based principal component analysis.

Therefore, some of the used equations may have better results in specific areas implementing specific band ratios than others taking into consideration the use of OLI- 8 as a source of remote sensing data $[23,49]$.

Estimated values of soil salinity index-9 were then used to map and classify soil salinity in the whole study area. Regular interpolation technique with six different smoothing Kernel functions is implemented and evaluated according to Krivoruchko et al. [50] as shown in Table 3 and Figure 5.

In Figure 5, only 3\% of Wadi Al Dawasir area is categorized to be with low soil salinity followed by $10 \%$ of moderate soil salinity class. Meanwhile, more than half of the study area is subjected to a higher concentration of soil salinity (52\%). In addition, there are soils in Wadi Al Dawasir which cannot be used for the current agricultural practice due to extreme condition of soil salinity (35\%).

Kernel function of polynomial-5 was used to produce a thematic soil salinity map in the study area (Figure 6). Based on Soil Survey approach in conjunction with natural breaks classification method was used to reclassify the prediction risk maps into four classes according to their toxicity levels into Low, Moderate, High, and Extreme [51, 52]. The role of the classifier is based on squared error minimization from a class's means by creating internally homogenous groups but maintaining heterogeneity between classes.

Figure 7 shows the percentages of Wadi Al Dawasir agricultural area which were fallen into the four soil salinity classes based on NDVI estimation. The total agricultural area 
TABLE 3: Evaluation of different interpolation kernels function.

\begin{tabular}{lcccccc}
\hline & & \multicolumn{4}{c}{ Kernel function } \\
& Exponential & Gaussian & Quartic & Epanechnikov & Polynomial-5 & Constant \\
\hline Regression function & $0.006 X+29339$ & $-0.001 X+29659$ & $0.003 X+29477$ & $-0.005 X+29778$ & $0.005+29368$ & $-0.001 X+29679$ \\
Mean & 1383 & 1421 & 1378 & 1412 & $\mathbf{1 3 5 5}$ & 1428 \\
Root mean square & 4251 & 4257 & 4250 & 4257 & 4253 & 4266 \\
Mean standardized & 0.0065 & 0.0067 & 0.0065 & 0.0066 & $\mathbf{0 . 0 0 6 4}$ & 0.0067 \\
Root mean square standardized & 0.0201 & 0.0201 & 0.0202 & 0.0201 & 0.0202 & 0.0200 \\
Average standard error & 211114 & 211797 & 210334 & 211526 & $\mathbf{2 0 9 6 4 1}$ & 212674 \\
\hline
\end{tabular}

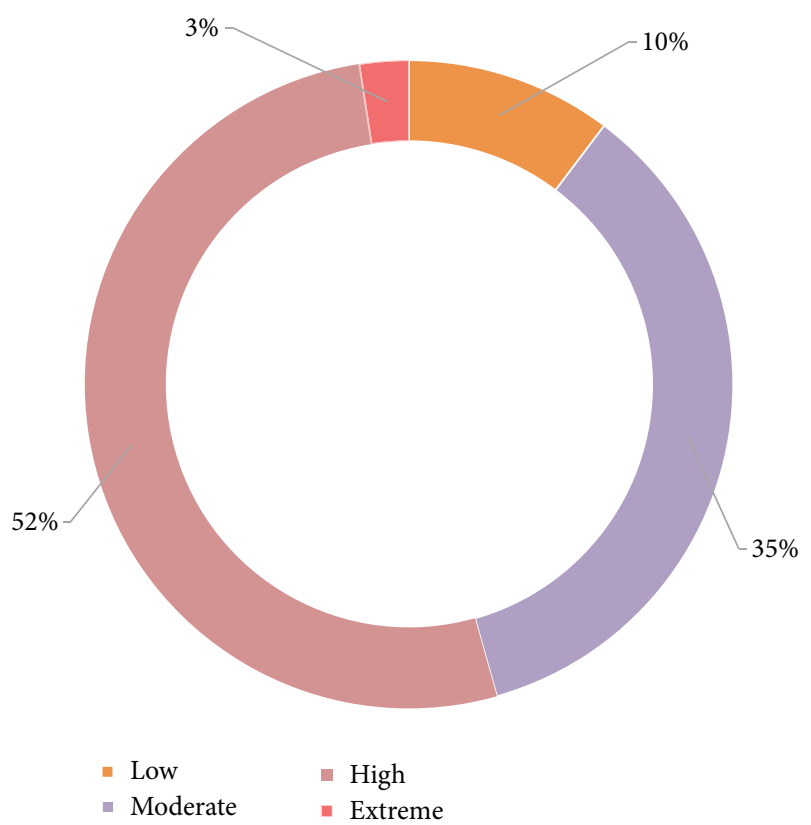

Figure 5: Soil Salinity classes in Wadi Al Dawasir area.

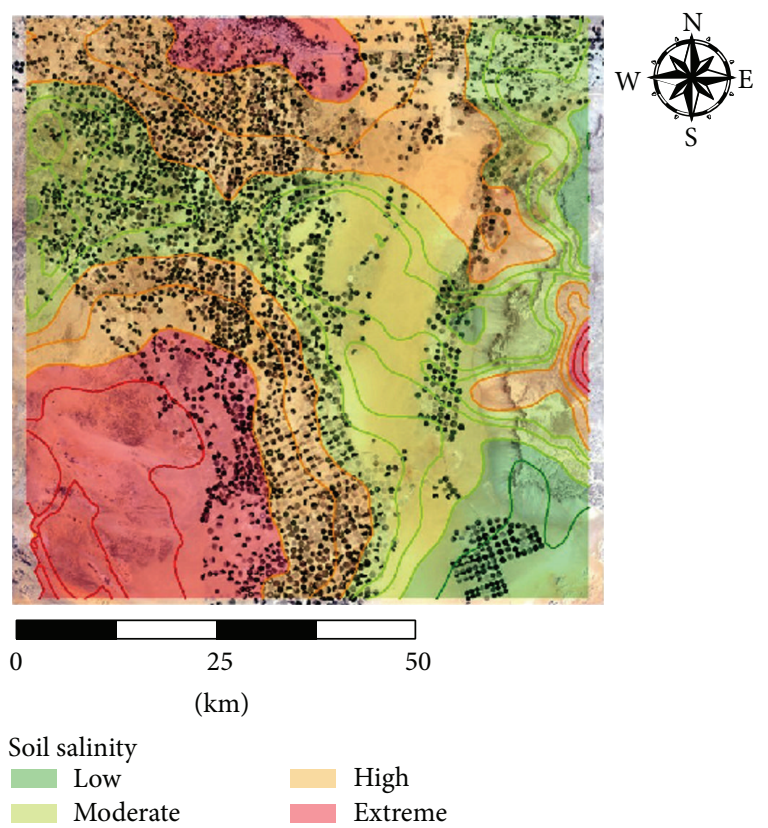

FIgURE 6: Soil salinity map in Wadi Al Dawasir.

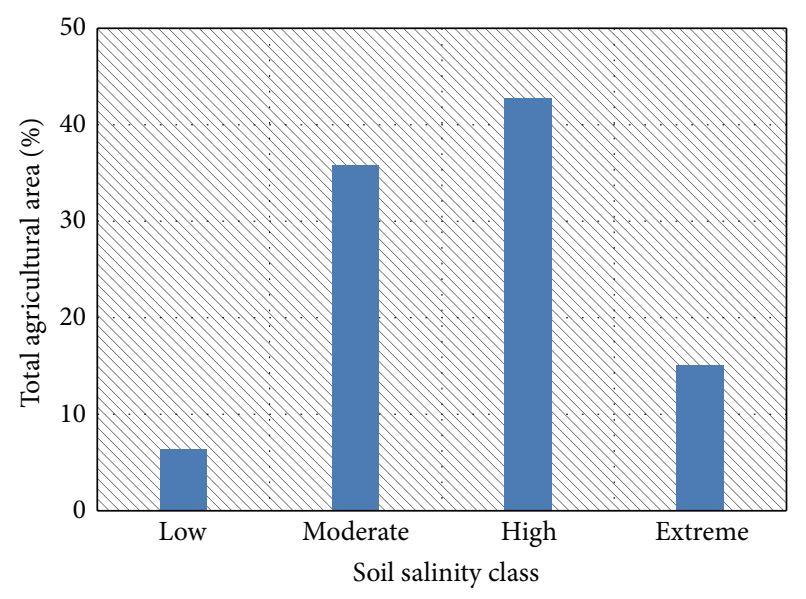

FIgURE 7: Contribution of different soil salinity classes to the total agricultural area.

in Wadi Al Dawasir expressed low soil salinity contribution (6.5\%). Those areas are the best to preserve the natural resources and the agricultural practice in Wadi Al Dawasir. About $36 \%$ of the total agricultural area constantly needs efforts to sustain the current agriculture practice. Both of the aforementioned classes are less than the half of the cropped area of Wadi Al Dawasir. Closer to 58\% of the cultivated area is on improper soils due to its high salinity content.

Soil salinity index-9, as a remotely sensed indicator, typically depends on the vegetation growing conditions which are helpful for mapping spatially the distribution of soil salinity [53]. The response of certain features of crop stress, dehydration, and senescence using vegetation indices have been examined to determine their response in different spectra [54, 55]. According to Carter [54], cell structure damage and chlorophyll reduction could be reliably measured using reduced near infrared reflectance (NIR) and increased visible reflectance (VIS) among several plant species in response to stress. Tilley et al. [53] also investigated salt stress responses in both of VIS and NIR. Normalized difference vegetation index (NDVI) as one of the most implemented vegetation indices has been inspected in abundant scholarly work by using the different vegetation reflectance to estimate soil salinity [40].

\section{Conclusions}

Crop production in Wadi Al Dawasir is completely dependent on underground water resources represented in 
artesian wells. The use of the underground water resources is annually overexploited due to the horizontal expansion of the agricultural land. The driving forces of the agricultural land expansion and the use of the underground water resources are controlled only by the Ministry of Water and Electricity but not by the local inhabitants. Such uncontrolled conditions put the water resources and the soils of Wadi Al Dawasir in jeopardy. The use of excess irrigational water to cope with the extremely arid conditions in the study area continuously creates more drainage problems as the agricultural areas in Wadi Al Dawasir have no drainage system by any means. Water logging and soil salinization are common problems in agricultural areas described by no drainage system. Consequently, the hydrological sceneries and the geomorphological patterns of arid lands are very important aspects to be considered in any rational development plan. Soil salinity indices are site/condition specific and soil salinity index-9 is the best to represent soil salinity values in the current study area. The current agricultural practices in Wadi Al Dawasir are obviously not the optimum water and/or soil resources management. More than half of the study area is characterized by either high or extreme soil salinity classes. Crop reallocation and rational water use may serve the goal of sustainability to keep the current agricultural practice in Wadi Al Dawasir. Monitoring and temporal soil salinity investigation are the keystone exercise required for adequate natural resources management plans in the near future.

\section{Conflict of Interests}

The author declares that there is no conflict of interests regarding the publication of this paper.

\section{Acknowledgment}

This project was funded by the Deanship of Scientific Research (DSR), King Abdulaziz University, Jeddah, under Grant no. 137-155-1436-G. The author, therefore, acknowledges and thanks DSR for technical and financial support.

\section{References}

[1] Ministry of Water and Electricity (MOWE), Annual Report, Ministry of Water and Electricity (MOWE), Riyadh, Saudi Arabia, 2008

[2] A. W. Abderrahman, "Water demand management in Saudi Arabia," in Water Management in Islam, N. I. Faruqui, A. K. Biswas, and M. J. Bino, Eds., IDRC, 2001.

[3] World Bank, "A water sector assessment report on the countries of the co-operation Council of the Arab States of the Gulf," Tech. Rep. 32539-MNA, World Bank, 2005.

[4] K. H. Al-Zahrani, "Water demand management in the Kingdom of Saudi Arabia," Conference of the International Journal of Arts \& Sciences, vol. 2, no. 3, pp. 68-76, 2010.

[5] K. H. Al-Zahrani and M. B. Baig, "Water in the kingdom of Saudi Arabia: sustainable management options," The Journal of Animal and Plant Sciences, vol. 21, no. 3, pp. 601-604, 2011.
[6] M. Elhag and J. A. Bahrawi, "Conservational use of remote sensing techniques for a novel rainwater harvesting in arid environment," Environmental Earth Sciences, vol. 72, no. 12, pp. 4995-5005, 2014.

[7] J. M. Bradd, W. A. Milne-Home, and G. Gates, "Overview of factors leading to dryland salinity and its potential hazard in New South Wales, Australia," Hydrogeology Journal, vol. 5, no. 1, pp. 51-67, 1997.

[8] D. R. Williamson, "Land degradation processes and water quality effects, waterlogging and salinity," in Farming Action Catchment Reaction, The Effect of Dry-Land Farming on the Natural Environment, J. Williams, R. A. Hook, and H. L. Gascoigne, Eds., pp. 162-190, CSIRO Publishing, Collingwood, Va, USA, 1998.

[9] E. Houk, M. Frasier, and E. Schuck, "The agricultural impacts of irrigation induced waterlogging and soil salinity in the Arkansas Basin," Agricultural Water Management, vol. 85, no. 1-2, pp. 175-183, 2006.

[10] R. Jones and G. Marshall, "Land salinization, waterlogging and the agricultural benefits of a surface drainage scheme in Benerembah irrigation district," Review of Marketing and Agricultural Economics, vol. 60, pp. 173-189, 1992.

[11] R. George, D. McFarlane, and B. Nulsen, "Salinity threatens the viability of agriculture and ecosystems in Western Australia," Hydrogeology Journal, vol. 5, no. 1, pp. 6-21, 1997.

[12] F. Konukcu, J. W. Gowing, and D. A. Rose, "Dry drainage: a sustainable solution to waterlogging and salinity problems in irrigation areas?" Agricultural Water Management, vol. 83, no. 1-2, pp. 1-12, 2006.

[13] S. Abdel-Dayem, S. Abdel-Gawad, and H. Fahmy, "Drainage in Egypt: a story of determination, continuity, and success," Irrigation and Drainage, vol. 56, no. 1, pp. 101-111, 2007.

[14] R. S. Dwivedi, "Monitoring of salt-affected soils of the IndoGangetic alluvial plains using principal component analysis," International Journal of Remote Sensing, vol. 17, no. 10, pp. 19071914, 1996.

[15] L. Chaturvedi, K. R. Carver, J. C. Harlan, G. D. Hancock, F. V. Small, and K. J. Dalstead, "Multispectral remote sensing of saline seeps," IEEE Transactions on Geoscience and Remote Sensing, vol. 21, no. 3, pp. 239-251, 1982.

[16] R. P. Singh and S. K. Srivastav, "Mapping of waterlogged and salt-affected soils using microwave radiometers," International Journal of Remote Sensing, vol. 11, no. 10, pp. 1879-1887, 1990.

[17] M. Menenti, A. Lorkeers, and M. Vissers, "An application of thematic mapper data in Tunisia," International Journal of Applied Earth Observation, vol. 1, pp. 35-42, 1986.

[18] M. A. Mulders and G. F. Epema, "The thematic mapper: a new tool for soil mapping in arid areas," International Journal of Applied Earth Observation, vol. 1, pp. 24-29, 1986.

[19] S. K. Saha, M. Kudrat, and S. K. Bhan, "Digital processing of Landsat TM data for wasteland mapping in parts of Aligarh District (Uttar Pradesh), India," International Journal of Remote Sensing, vol. 11, no. 3, pp. 485-492, 1990.

[20] B. R. Rao, R. S. Dwivedi, L. Venkataratnam et al., "Mapping the magnitude of sodicity in part of Indo-Gangetic plains of Uttar Pradesh, Northern India using Landsat data,' International Journal of Remote Sensing, vol. 12, no. 3, pp. 1419-1425, 1991.

[21] M. Y. Naseri, Characterization of salt-affected soils for modeling sustainable land management in the semi-arid environment; a case study in the Gorgan region, Northeast Iran [Ph.D. thesis], Ghent University, Ghent, Belgium, 1998. 
[22] A. A. Darvishsefat, M. H. Damavandi, M. Jafari, and G. R. Zehtabiyan, "Assessing of Landsat TM images for using in soil salinity classification," Journal of Desert, vol. 5, no. 2, 2000.

[23] T. Zhang, G. Zhao, C. Chang et al., "Information extraction method of soil salinity in typical areas of the yellow river delta based on landsat imagery," Agricultural Sciences, vol. 06, no. 01, pp. 71-77, 2015.

[24] L. M. Montandon and E. E. Small, "The impact of soil reflectance on the quantification of the green vegetation fraction from NDVI," Remote Sensing of Environment, vol. 112, no. 4, pp. 1835-1845, 2008.

[25] B. D. Wardlow and S. L. Egbert, "Large-area crop mapping using time series MODIS $250 \mathrm{~m}$ NDVI data: an assessment for the US Central Great Plains," Remote Sensing of Environment, vol. 112, no. 3, pp. 1096-1116, 2008.

[26] Z. P. Yang, J. X. Gao, C. P. Zhou et al., "Spatio-temporal changes of NDVI and its relation with climatic variables in the source regions of the Yangtze and Yellow rivers," Journal of Geographical Sciences, vol. 21, no. 6, pp. 979-993, 2011.

[27] A. E. K. Douaoui, H. Nicolas, and C. Walter, "Detecting salinity hazards within a semiarid context by means of combining soil and remote-sensing data," Geoderma, vol. 134, no. 1-2, pp. 217230, 2006.

[28] G. Jiapaer, X. Chen, and A. M. Bao, "A comparison of methods for estimating fractional vegetation cover in arid regions," Agricultural and Forest Meteorology, vol. 151, no. 12, pp. 16981710, 2011.

[29] B. R. M. Rao, R. S. Dwivedi, L. Venkataratnam et al., "Mapping the magnitude of sodicity in part of the Indo-Gangetic plains of Uttar Pradesh, northern India using Landsat-TM data," International Journal of Remote Sensing, vol. 12, no. 3, pp. 419425,1991

[30] A. Srivastava, N. K. Tripathi, and K. V. G. K. Gokhale, "Mapping groundwater salinity using IRS-1B LISS II data and GIS techniques," International Journal of Remote Sensing, vol. 18, no. 13, pp. 2853-2862, 1997.

[31] R. S. Dwivedi and K. Sreenivas, "Delineation of salt-affected soils and waterlogged areas in the Indo-Gangetic plains using IRS-1C LISS-III data," International Journal of Remote Sensing, vol. 19, no. 14, pp. 2739-2751, 1998.

[32] M. Elhag and J. Bahrawi, "Cloud coverage disruption for groundwater recharge improvement using remote sensing techniques in Asir region, Saudi Arabia," Life Science Journal, vol. 11, no. 1, pp. 192-200, 2014.

[33] R. Goossens, M. De Dapper, A. Gad, and Th. Ghabour, "A model for monitoring and prediction of soil salinity and waterlogging in the Ismailia area (Egypt) based on remote sensing and GIS," in Proceedings of the International Symposium on Operationalization of Remote Sensing, vol. 6, pp. 97-107, ITC, Enschede, The Netherlands, April 1993.

[34] S. Casas, "Salinity assessment based on combined use of remote sensing and GIS," in Use of Remote Sensing Techniques in Irrigation and Drainage Unknown, pp. 141-150, FAO, Rome, Italy, 1995.

[35] R. Shaw, "Estimation of the electrical conductivity of saturation extracts from the electrical conductivity of 1:5 soil: water suspensions and various soil properties," Project Report Series QO94025, Department of Primary Industries, Queensland, Australia, 1994.

[36] P. S. Chavez Jr., "Image-based atmospheric correctionsrevisited and improved," Photogrammetric Engineering and Remote Sensing, vol. 62, no. 9, pp. 1025-1036, 1996.
[37] U. Beisl, J. Telaar, and M. Schönermark, "Atmospheric correction, reflectance calibration and BRDF correction for ADS40 image data," in Proceedings of the International Archives of the Photogrammetry, Remote Sensing and Spatial Information Sciences, vol. 87, part B7, pp. 7-12, Beijing, China, 2008.

[38] G. E. P. Box, "Some theorems on quadratic forms applied in the study of analysis of variance problems, II. Effects of inequality of variance and of correlation between errors in the two-way classification," Annals of Mathematical Statistics, vol. 25, no. 3, pp. 484-498, 1954.

[39] A. Dehni and M. Lounis, "Remote sensing techniques for salt affected soil mapping: application to the Oran Region of Algeria," Procedia Engineering, vol. 33, pp. 188-198, 2012.

[40] A. Allbed and L. Kumar, "Soil salinity mapping and monitoring in arid and semi-arid regions using remote sensing technology: a review," Advances in Remote Sensing, vol. 02, no. 04, pp. 373385, 2013.

[41] A. K. Koshal, "Spectral characteristics of soil salinity areas in parts of South-West Punjab through remote sensing and GIS," International Journal of Remote Sensing and GIS, vol. 1, no. 2, pp. 84-89, 2012.

[42] L. Lei, T. Tiyip, J.-L. Ding, H.-N. Jiang, and A. Kelimu, "Study on the soil salinization monitoring based on measured hyperspectral and HSI data," Spectroscopy and Spectral Analysis, vol. 34, no. 7, pp. 1948-1953, 2014.

[43] D. J. Major, F. Baret, and G. Guyot, "A ratio vegetation index adjusted for soil brightness," International Journal of Remote Sensing, vol. 11, no. 5, pp. 727-740, 1990.

[44] N. M. Khan, V. V. Rastoskuev, Y. Sato, and S. Shiozawa, "Assessment of hydrosaline land degradation by using a simple approach of remote sensing indicators," Agricultural Water Management, vol. 77, no. 1-3, pp. 96-109, 2005.

[45] A. Bannari, A. M. Guedon, A. El-Harti, F. Z. Cherkaoui, and A. El-Ghmari, "Characterization of slightly and moderately saline and sodic soils in irrigated agricultural land using simulated data of advanced land imaging (EO-1) sensor," Communications in Soil Science and Plant Analysis, vol. 39, no. 19-20, pp. 27952811, 2008.

[46] A. Abbas and S. Khan, "Using remote sensing techniques for appraisal of irrigated soil salinity," in Proceedings of the International Congress on Modelling and Simulation (MODSIM '07), L. Oxley and D. Kulasiri, Eds., pp. 2632-2638, Modelling and Simulation Society of Australia and New Zealand, Brighton, UK, December 2007.

[47] C. W. Zhang, J. K. Tang, X. J. Yu, C. L. Wang, and S. J. Mi, "Quantitative retrieval of soil salt content based on remote sensing in the Yellow River delta," Journal of Graduate University of Chinese Academy of Sciences, vol. 30, pp. 220-227, 2013.

[48] J.-L. Ding, M.-C. Wu, H.-X. Liu, and Z.-G. Li, "Study on the soil salinization monitoring based on synthetical hyperspectral index," Spectroscopy and Spectral Analysis, vol. 32, no. 7, pp. 1918-1922, 2012.

[49] D. Abdellatif and L. Mourad, "Remote sensing techniques for salt affected soil mapping: application to the Oran Region of Algeria," Procedia Engineering, vol. 33, pp. 188-198, 2012.

[50] K. Krivoruchko, A. Gribov, and E. Krause, "Multivariate areal interpolation for continuous and count data," Procedia Environmental Sciences, vol. 3, pp. 14-19, 2011.

[51] Soil Survey Staff, Keys to Soil Taxonomy, United States Department of Agriculture, Natural Resources Conservation Service, 10th edition, 2006. 
[52] B. Jiang, "Head/tail breaks: a new classification scheme for data with a heavy-tailed distribution," The Professional Geographer, vol. 65, no. 3, pp. 482-494, 2013.

[53] D. R. Tilley, M. Ahmed, J. H. Son, and H. Badrinarayanan, "Hyperspectral reflectance response of freshwater macrophytes to salinity in a brackish subtropical marsh," Journal of Environmental Quality, vol. 36, no. 3, pp. 780-789, 2007.

[54] G. A. Carter, "Responses of leaf spectral reflectance to plant stress," American Journal of Botany, vol. 80, no. 3, pp. 239-243, 1993.

[55] A. Psilovikos and M. Elhag, "Forecasting of remotely sensed daily evapotranspiration data over Nile Delta region, Egypt," Water Resources Management, vol. 27, no. 12, pp. 4115-4130, 2013. 


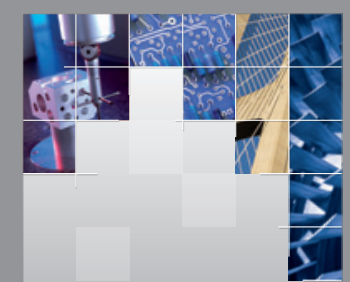

\section{Enfincering}
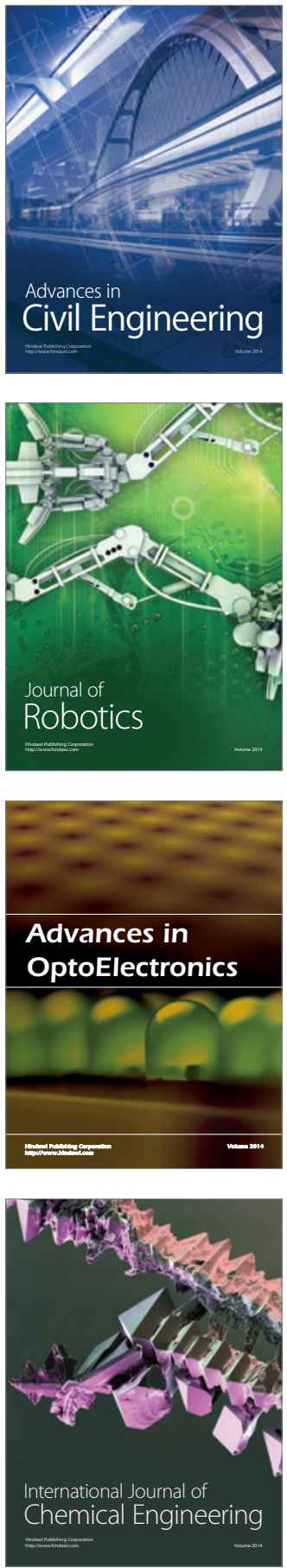

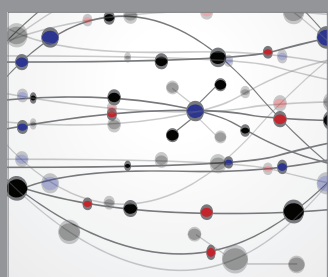

The Scientific World Journal

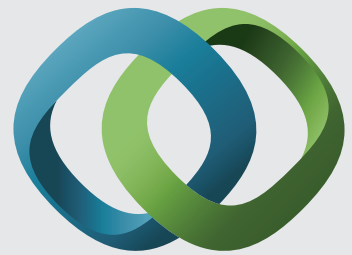

\section{Hindawi}

Submit your manuscripts at

http://www.hindawi.com
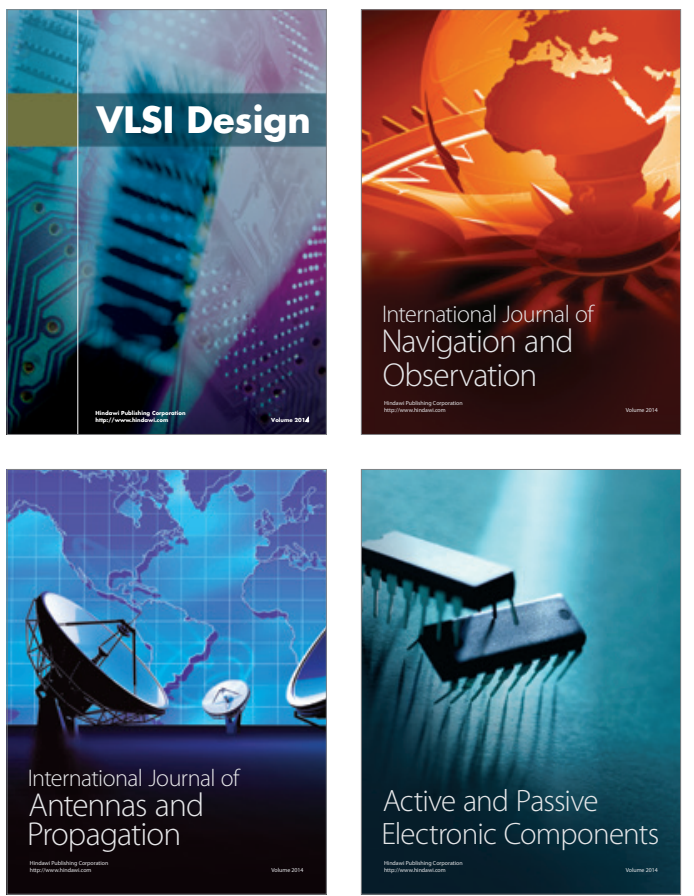
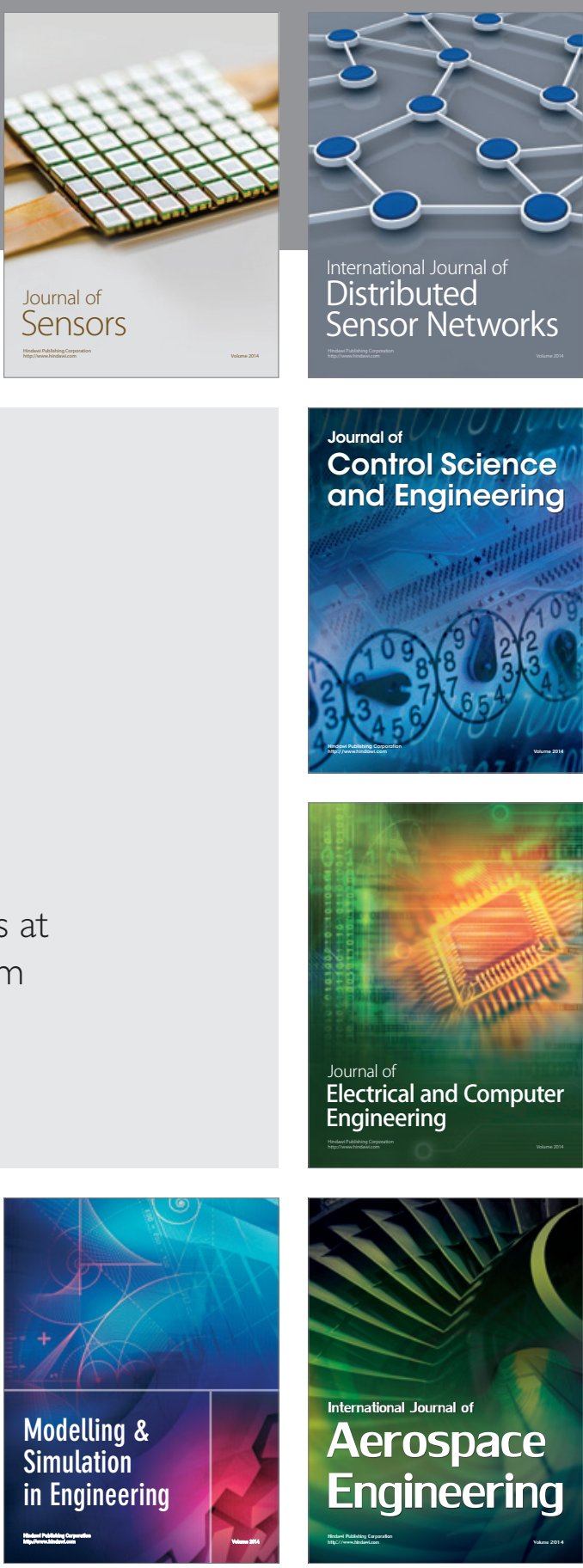

International Journal of

Distributed

Sensor Networks

Journal of

Control Science

and Engineering
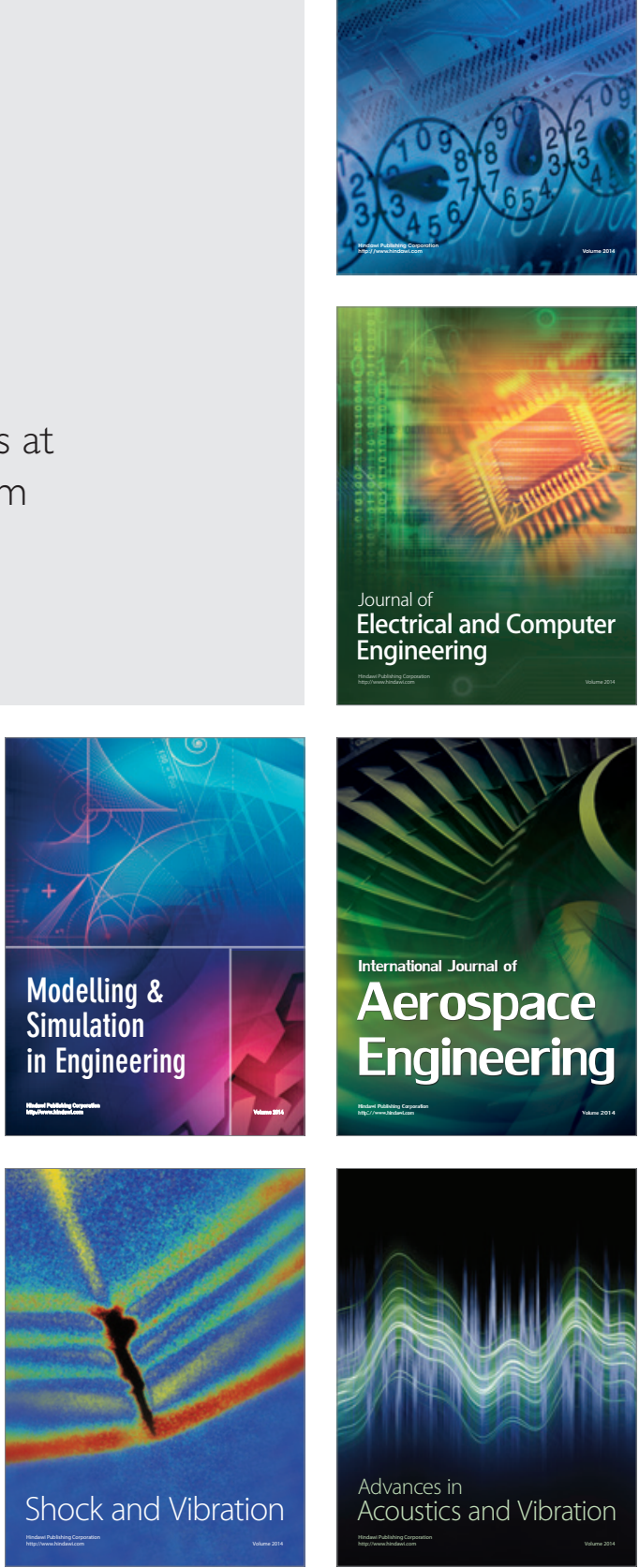